\title{
Entering New Golden Era in the Management and the Prevention of Diabetic Retinopathy
}

\author{
Samir Touma ${ }^{1}$, Mathieu Gauvin ${ }^{2}$ and Hadi Chakor ${ }^{3 *}$ \\ ${ }^{1}$ Faculty of Medicine, McGill University, Canada \\ ${ }^{2}$ Department of Ophthalmology \& Neurology-Neurosurgery Research Institute of the McGill University Health Centre/Montreal Children's Hospital \\ Montreal, Canada \\ ${ }^{3}$ Chief Medical Officer of Diagnos Inc, Canada
}

Submission: July 14, 2018; Published: July 23, 2018

*Corresponding author: Hadi Chakor, Chief Medical Officer of Diagnos Inc., 7005 Taschereau Blvd, Suite 340, Brossard, QC J4Z 1A7, Canada, Tel: +15148021503/+14506788882ext.257; Email: hchakor@diagnos.ca

\section{Opinion}

Diabetes mellitus is one of the first diseases defined, with the oldest known description being an Egyptian manuscript from 1500 BCE [1]. Throughout history, different terms and tests were used to describe this disease; often referring to the sweet taste it gives urine. This unique characteristic even led certain physicians to taste their patients' urine in order to screen for the disease. Since then, multiple screening tools have been used and developed for that disease. It is now more important than ever to use accurate and specific screening tests given the fact that diabetes mellitus is one of the most prevalent diseases, affecting more than 400 million people worldwide [1,2]. Diabetes has long-term micro and macro vascular complications affecting predominantly the kidneys, the heart, the nervous system and the eyes.

Diabetic retinopathy is one of the most common complications of the disease, affecting around 4 patients out of 5 who had the disease for over 20 years. It is a serious and frequent complication, being the leading the cause of blindness amongst working-aged patients. Over the past 15 years, many countries appear to have made a genuine effort to reduce the complications and consequences due to diabetic retinopathy. The St. Vincent Declaration sets a benchmark for the planning of future delivery of care to diabetic patients [3]. Multiple national screening programs have been developed using digital fundus photography, effective screening of diabetes has been proven to reduce the risks of visual impairment and the severity of the complications. The potential results of screening with digital retinography are particularly well documented in a short publication in the American Academy of Ophthalmology Basic and Clinical Science Course Series.

The fundus photos are analyzed by health care professionals to determine the presence and grade of the retinopathy. However, due to the overwhelming prevalence of the disease and the limited number of qualified professionals, these screening methods have major obstacles to their practical application [4]. Also, the results can fluctuate a lot due to variations between the interpreters. It is critical to identify the lesions as early as possible as this increases the success of the different possible treatments. This is where we think artificial intelligence can play a significant role. The use of artificial intelligence in medicine has been gaining popularity in multiple fields, especially those where there is a need for accuracy and rapidity. Chronic conditions, such as diabetes, require many follow-up visits and are a substantial burden on the health care system. They are the leading cause of death in Canada and severely affect the quality of life of patients [5]. Therefore, there is an urgent need to develop tools that will relieve that weight. Artificial intelligence can be of a great help and we believe that its use in the screening process for diabetic retinopathy would improve diagnosis and management of the disease both in developed and developing countries [6-8].

The incredible potential of this technology is that it can further learn and improve based on the physicians' needs and as new data is being analyzed $[8,9]$. From a practical point of view, last year in Mexico City, a telemedicine program using an AI application was successfully implemented and executed on a large-scale population with significant improvements. Around 79,000 patients with diabetes and prediabetes were screened through that highly efficient and secure detection tool, achieving an accuracy of $0.95[10,11]$. Those results highlight the strength and simplicity of this automatic telemedicine program based on AI. It has the potential to maximize access and to standardize monitoring during follow-up visits, while achieving a high costeffectiveness.

Artificial intelligence should play a major role in our healthcare systems to improve patient care. We think that this 


\section{Current Research in Diabetes \& Obesity Journal}

technology will open new horizons and will help bring the complications of diabetes to the forefront and at the same time, fuel the process of change.

\section{References}

1. Poretsky L (2017) Principles of diabetes mellitus. Springer International.

2. Nathan DM (2015) Diabetes: advances in diagnosis and treatment JAMA 314(10): 1052-1062.

3. Katharine A, Deborah B (2016) Screening for diabetic retinopathy in Europe. The Liverpool Declaration, Satellite meeting to EASDec, The Liverpool Declaration, Manchester, UK.

4. Bolster NM, Giardini ME, Bastawrous A (2015) The diabetic retinopathy screening workflow: potential for smartphone imaging. J Diabetes Sci Technol 10(2): 318-324.

5. World Health Organization (2005) Preventing chronic disease: a vital investment. Geneva, Switzerland, p. 182.

6. Abramoff MD, Lou Y, Erginay A, Clarida W, Amelon R, et al. (2016) Improved automated detection of diabetic retinopathy on a publicly available dataset through integration of deep learning. Invest Ophthalmol Vis Sci 57(13): 5200-5206

7. Phan TV, Seoud L, Chakor H, Cheriet F (2016) Automatic screening and grading of age-related macular degeneration from texture analysis of fundus images. J Ophthalmol 2016: 5893601.

8. Seoud L, Hurtut T, Chelbi J, Cheriet F, Langlois JM (2016) Red lesion detection using dynamic shape features for diabetic retinopathy screening. IEEE Trans Med Imaging 35(4): 1116-1126.

9. Mookiah MR, Acharya UR, Chua CK, Lim CM, Ng EY, et al. (2013) Computer-aided diagnosis of diabetic retinopathy: a review. Comput Biol Med 43(12): 2136-2155.

10. Agustín Lara E, Iván Delgado E, Jorge M, Sanchez IADLB, Hadi C (2018) Fundus examination to detect computer-assisted retinopathy, a strategy to improve the quality of care in people with diabetes. Diabetes Hoy 17: 16-20.

11. Jorge Guerrero A, Hadi C (2017) Teasing out the evidence of primary care-based Tele-retinal diabetic retinopathy screening after implementing a large program from ISSSTE across Mexico City and Metropolitan area. International Diabetes Federation, USA.

\section{Your next submission with Juniper Publishers will reach you the below assets}

- Quality Editorial service

- Swift Peer Review

- Reprints availability

- E-prints Service

- Manuscript Podcast for convenient understanding

- Global attainment for your research

- Manuscript accessibility in different formats

(Pdf, E-pub, Full Text, Audio)

- Unceasing customer service

Track the below URL for one-step submission https://juniperpublishers.com/online-submission.php 